\title{
Angiotensin for septic shock unresponsive to noradrenaline
}

\author{
Mauricio Yunge, Andy Petros
}

\begin{abstract}
Two children with severe septic shock are reported. One had meningococcal septicaemia and the other Escherichia coli septicaemia. They remained hypotensive despite high concentrations of conventional inotropes and vasopressors. In one child, using a pulmonary artery catheter, extended haemodynamic variables were measured. To restore blood pressure, in both cases, an infusion of angiotensin II was used; there was significant improvement in clinical status, resulting in a rapid reduction in the concentration of inotropes required. Both patients successfully survived their septic episodes. Angiotensin II in cases of severe refractory septic hypotension in the paediatric population offers an extra therapeutic manoeuvre.

(Arch Dis Child 2000;82:388-389)
\end{abstract}

Keywords: sepsis; hypotension; angiotensin

Paediatric Intensive Care Unit, Great Ormond Street Hospital for Children NHS Trust, London WC1 3JH, UK

$M$ Yunge

A Petros

Correspondence to: Dr Petros

email: andy.petros@gosh-tr. nthames.nhs.uk

Accepted 5 January 2000



Figure 1 Mean arterial pressure (MAP), indexed systemic vascular resistance (SVRI) $\left(\right.$ dyne $\left.\times \mathrm{s} / \mathrm{cm}^{5} \times \mathrm{m}^{2}\right)$, and inotrope concentration used in case 1. ADREN, adenaline; NA, noradrenaline; ANGIOT, angiotensin. component caused by fluid loss and decreased cardiac function. If successful vasoconstriction can be achieved, adequate mean arterial pressure may be obtained which may in turn improve central perfusion.

\section{Case 1}

A previously fit 4 year old boy weighing $20 \mathrm{~kg}$ was admitted with a diagnosis of septic shock secondary to meningococcal infection. He was poorly perfused and had a typical generalised purpuric rash. His white cell count was $1.5 \times$ $10^{9}$, fibrinogen $41.16 \mu \mathrm{mol} / 1$, and platelets $80 \times$ $10^{9} / 1$. His paediatric risk of mortality (PRISM) score in the first 24 hours was 29 , with a predicted risk of mortality of $72.3 \%$ and a Glasgow Meningococcal Septicaemia Prognostic score of 11 . He was resuscitated with fluids, given antibiotics, and mechanical ventilation was commenced. His mean arterial pressure was $50 \mathrm{~mm} \mathrm{Hg}$, maintained with an infusion of dopamine $15 \mu \mathrm{g} / \mathrm{kg} / \mathrm{min}$, and adrenaline 0.5 $\mu \mathrm{g} / \mathrm{kg} / \mathrm{min}$. Echocardiography revealed moderate biventricular impairment with left ventricular functional shortening of $22 \%$ (normal value $35-45 \%)$.

Despite aggressive fluid replacement (approximately $120 \mathrm{ml} / \mathrm{kg}$ ) inotrope concentrations had to be increased (dopamine $20 \mu \mathrm{g} / \mathrm{kg} / \mathrm{min}$, adrenaline $1.1 \mu \mathrm{g} / \mathrm{kg} / \mathrm{min}$ ) and noradrenaline $1.0 \mu \mathrm{g} / \mathrm{kg} / \mathrm{min}$ introduced, resulting in a mean arterial pressure of $73 \mathrm{~mm} \mathrm{Hg}$. At this stage a pulmonary artery catheter was inserted. Cardiac index was $3.56 \mathrm{1} / \mathrm{m} / \mathrm{m}^{2}$ (normal value 2.8-3.0) and indexed systemic vascular resistance was 1438 dyne $\times \mathrm{s} / \mathrm{cm}^{5} \times \mathrm{tm}^{2}$ (normal value $>1400$ ). In view of the escalating inotrope requirements, rather than continuing to increase the concentration of the three inotropes being used, an infusion of angiotensin II (Ciba-Geigy, Germany) was started at $0.1 \mu \mathrm{g} / \mathrm{kg} / \mathrm{min}$ and increased to a maximum of $0.32 \mu \mathrm{g} / \mathrm{kg} / \mathrm{min}$, in order to try and achieve a degree of haemodynamic stability. Mean arterial pressure, cardiac index, and indexed systemic vascular resistance were all maintained (fig 1) during the angiotensin II infusion. In addition, it was possible to rapidly decrease the concentration of noradrenaline and adrenaline. Angiotensin II was used for 24 hours, providing an adequate blood pressure during this time; on day 5 inotropes were stopped, and the child was extubated on day 10 . He was discharged from intensive care 12 days after admission and from hospital 12 days later.

\section{Case 2}

A 4 year old boy $(18 \mathrm{~kg})$ with chronic renal failure secondary to posterior urethral valves, was receiving peritoneal dialysis at home 


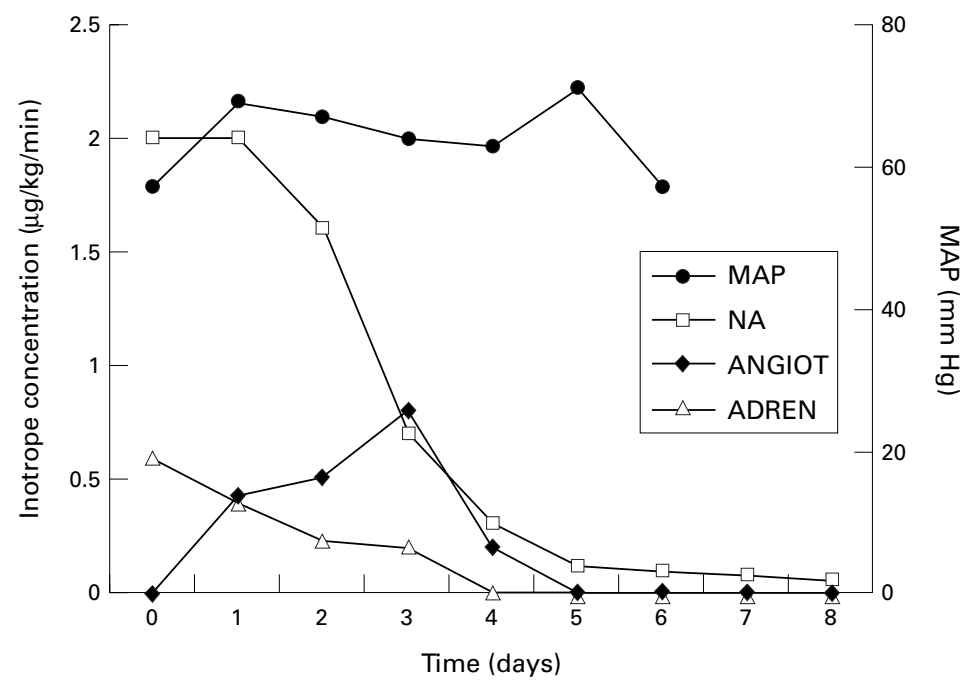

Figure 2 Mean arterial pressure (MAP) and inotrope concentration used in case 2. ADREN, adenaline; $N A$, noradrenaline; $A N G I O T$, angiotensin.

following an unsuccessful renal transplant and developed candida peritonitis. This progressed to septic shock and on admission he had a mean arterial pressure of $47 \mathrm{~mm} \mathrm{Hg}$. His PRISM score was 20, with a risk of mortality of $29 \%$. He was commenced on inotropes and haemofiltration. Dopamine $15 \mu \mathrm{g} / \mathrm{kg} / \mathrm{min}$ was started and was increased to $20 \mu \mathrm{g} / \mathrm{kg} / \mathrm{min}$. Adrenaline $0.4 \mu \mathrm{g} / \mathrm{kg} / \mathrm{min}$ was added and two days later noradrenaline $0.4 \mu \mathrm{g} / \mathrm{kg} / \mathrm{min}$ was started. Fourteen days after admission his condition deteriorated and he developed Escherichia coli septicaemia. Inotrope requirement increased to adrenaline $1.0 \mu \mathrm{g} / \mathrm{kg} / \mathrm{min}$ and noradrenaline $2 \mu \mathrm{g} / \mathrm{kg} / \mathrm{min}$. Angiotensin II was commenced at $0.4 \mu \mathrm{g} / \mathrm{kg} / \mathrm{min}$ and increased to $0.8 \mu \mathrm{g} / \mathrm{kg} / \mathrm{min}$; this permitted an immediate decrease of adrenaline to $0.2 \mu \mathrm{g} / \mathrm{kg} /$ min and noradrenaline to $0.7 \mu \mathrm{g} / \mathrm{kg} / \mathrm{min}$ (fig 2). Adrenaline was discontinued three days after angiotensin II was started. Noradrenaline 0.3 $\mu \mathrm{g} / \mathrm{kg} / \mathrm{min}$ was stopped on day 7 as was angiotensin II.

\section{Discussion}

Septic shock remains a significant cause of mortality in children. Despite new technology, new therapeutic strategies, and more potent and effective antimicrobials, the mortality rate from septic shock remains greater than $40 \%{ }^{2}$ Treatment of septic shock includes aggressive fluid resuscitation, ventilatory support, antibiotics, metabolic stability, and the use of inotropes and vasopressors. In most children, septic vasodilatation responds effectively to the use of adequate volume replacement and dopamine, adrenaline, and noradrenaline, leading to improved oxygen delivery and an increase of blood pressure. However, some cases fail to respond to this conventional management and may need above average doses of inotropes to increase the mean arterial pressure. The reasons for this lack of response in vasomotor tone in septic shock include a diminished pressor response to vasoconstrictors, ${ }^{3}$ an enhanced production of vasodilators such as prostaglandin and nitric oxide, ${ }^{4}$ probable alteration in intracellular calcium metabolism, and some adrenergic receptor down regulation.

There are successful reports in the literature of the use of angiotensin II in adults, in refractory septic shock unresponsive to noradrenaline. ${ }^{5}$ The dose of angiotensin II used in adults ranges from 0.05 to 1.6 $\mu \mathrm{g} / \mathrm{kg} / \mathrm{min}$. We used $0.32 \mu \mathrm{g} / \mathrm{kg} / \mathrm{min}$ in the first child and $0.8 \mu \mathrm{g} / \mathrm{kg} / \mathrm{min}$ in the second to achieve an adequate mean arterial pressure. No complications have been reported.

Angiotensin II is 40 times more potent than noradrenaline on a molar basis. ${ }^{6}$ Its onset of action is $10-20$ seconds with a half time of a few minutes; it is degraded to angiotensin III. Mechanisms of action include direct vasoconstriction by activating angiotensin I receptors, enhancement of peripheral noradrenergic neurotransmission, increased sympathetic discharge (CNS), and release of catecholamines from the adrenal medulla. In the treatment of paediatric septic shock not responding to the conventional drugs angiotensin II may have a useful role.

1 Goldman AP, Kerr SJ, Butt W, et al. Extracorporeal support for intractable cardiorespiratory failure due to meningococcal disease. Lancet 1997;349:466-9.

2 Baltodano A. Septic shock. Baillieres Clinical Paediatrics, Paediatric Intensive Care 1998;6:95-110.

3 Schaller MD, Weaber B, Nussberger J, et al. Angiotensin II, vasopressin and sympathetic activity in conscious rats with endotoxemia. Am F Physiol 1985;249:H1086-92.

4 Julou-Schaeffer G, Gray GA, Fleming I, et al. Loss of vascular responsiveness induced by endotoxin involves

Wray GM, Coakley JH. Severe septic shock unresponsive to noradrenaline. Lancet 1995;346:1604.

6 Jackson E, Garrison J. Renin and angiotensin. In: Goodman and Gilman. The pharmacological basis of therapeutics. McGraw Hill, 1996:737-43. 